Doi: $\underline{\mathrm{dx} . \text { doi.org/10.17921/2525-5320.2016.67-69 }}$

\title{
APLICABILIDADE DA PEDAGOGIA DE SCHOENSTATT NAS PRÁTICAS DOCENTES
}

\author{
Natália Colombo Gomes - Mater Ter Admirabilis * \\ Natacha Bolorino - Mater Ter Admirabilis * \\ Rosana Medeiros- Mater Ter Admirabilis *
}

Palavras-chave: Docentes. Práticas Docente. Pedagogia de Schoenstatt.

\section{INTRODUÇÃO}

A pedagogia de Schoenstatt representa para o docente um direcionamento para as suas práticas de educar visando o retorno do homem a Deus. O fundador desta pedagogia em questão difundiu a idéia de que a sociedade havia sofrido influências pela doença mecanicista, cujo a compartimentalização da vida iniciada com o advento do conhecimento humano (STRANG, 2015).

Neste sentido, a peça chave para a prática da pedagogia de Schoenstatt além da educação, é a formação da cidadania que constitui um impulso para a transformação da sociedade atual. Para isso, é preciso que os educadores eduquem sujeitos capazes de criar ou mudar a ordem social através de seu trabalho, baseado nos valores advindos da sociedade (LEITE, 2009).

Frente ao exposto verifica-se a essencialidade da aplicabilidade da Pedagogia de Schoenstatt nas instituições de ensino inseridas nas práticas cotidianas dos docentes, sendo essa uma forma de educar para transformações na sociedade.

O objetivo deste trabalho foi analisar a aplicabilidade da pedagogia de Schoenstatt na prática docente.

\section{MATERIAL E MÉTODOS}

Para elaboração desta revisão integrativa, formulou-se a seguinte questão: A pedagogia de Schoenstatt está sendo aplicada pelos docentes no período de 2000 a

\footnotetext{
* E-mail: nataliacolombogomes@hotmail.com

* E-mail: natachabolorino@hotmail.com

* E-mail: rosana.medeiros@sercomtel.com.br
} 
2016? A busca dos artigos foi realizada nas seguintes bases de dados: Literatura Latino-Americana e do Caribe em Ciências da Saúde, Medical Literature Analysis and Retrieval Sistem on-line, Scientific Electronic Library e periódicos da CAPES, por meio do descritor docentes juntamente com as palavras-chave "práticas docente" e "pedagogia de Schoenstatt". O levantamento das publicações ocorreu em julho de 2016, e foram encontradas 2 publicações, nos quais consistiram em ser artigos publicados em português, e estar disponíveis nas bases de dados selecionadas e que se tratassem da aplicação da Pedagogia de Schoenstatt como prática educadora. A análise dos dados foi realizada após leituras dos artigos.

\section{RESULTADO E DISCUSSÃO}

A amostra desta revisão totalizou 28 estudos, dos quais 26 foram encontrados no Google Scholar, 1 na Medical Literature Analysis and Retrieval Sistem on-line e 1 artigo na Literatura Latino-Americana e do Caribe em Ciências da Saúde. Assim, das 28 publicações elencadas, apenas 3 atenderam os critérios propostos e foram selecionadas para compor este estudo.

Dessa forma, o primeiro estudo publicado em 2008, tem como objetivo analisar os dados de uma das instituições de formação de professores do colégio Mãe de Deus, situado em Londrina. Ainda nesta vertente, no ano seguinte, foi publicado um estudo que trata-se de uma investigação para informar os interessados pelas questões relativas à formação de educadores e ao ideário pedagógico desta mesma instituição em questão (LEITE, 2008; LEITE, 2009).

Já o terceiro estudo, publicado em 2015, analisa as recomendações em relação à (in)disciplina dos alunos, também desta instituição, entendendo a temática como um critério fundamentalmente importante para a consolidação das práticas docente (STRANG, 2015).

\section{CONCLUSÃO}

Os resultados apresentados permitiram concluir que a Pedagogia de Schoenstatt está inserida no âmbito das práticas docentes, com a finalidade de educar para que os educandos se tornem capazes de usar o conhecimento obtido para ser a diferença dentro de uma sociedade desigual e não meros receptores de um saber desvinculado da sociedade. 
Sugere-se que mais estudos sejam realizados para aumentar as evidências científicas, bem como disseminar os conhecimentos acerca da aplicabilidade.

\section{REFERÊNCIAS}

LEITE, S.R.M.; MARQUES, E.F.; SILVA, M.R.S. Formação de professores: o ideário pedagógico do Colégio Mãe de Deus em Londrina. In: CONGRESSO NACIONAL DE EDUCAÇÃO, 9; e ENCONTRO BRASILEIRO DE PSICOPEDAGOGIA, 3. Anais..., 2009, PUCPR.

LEITE, S.R.M.; MARQUES, F.E.; ALBERTONI, C.R. O ideário pedagógico na formação de professores do colégio Mãe de Deus em Londrina. In: SEMINÁRIO DO TRABALHO - TRABALHO, ECONOMIA, 6; e EDUCAÇÃO NO SÉCULO XXI. Marília. Anais... Marilia: Gráfica Massoni, p.1-12, 2008.

STRANG, B.L.S. et al. Cartas como escrita do tempo: a resposta pedagógica Schoesttatiana para a Indisciplina dos "Brasileirinhos". UNOPAR Cient., Ciênc. Human. Educ., v.16, n.5, p.500-506, 2015. 